\title{
Harmonic Mitigation Potential of Shunt Harmonic Impedances and the Influence of Background Distortion
}

\author{
Wouter R.A. Ryckaert, Member, IEEE, Jozef A.L. Ghijselen, Member, IEEE, and \\ Jan A.A. Melkebeek, Senior Member, IEEE
}

\begin{abstract}
Although complete compensation is only possible using true active filters, shunt harmonic impedances (SHI) have been shown to provide a considerable reduction of the harmonic propagation. In this paper, the mitigation potential of different shunt harmonic impedances is investigated, together with their VA-rating. It is shown that a resistive impedance of 1 pu for all harmonics is very effective, especially in the case of power system resonances. The analysis presented considers also the influence of the PHI on the line current injected into the power system when background distortion is present.

To take into account the interaction between harmonics, simulations are performed in the presence of a realistic non-linear load, instead of the common harmonic current source modelling approach.
\end{abstract}

Index Terms-Harmonics, Power Quality, Shunt Harmonic Impedances, Background Distortion.

\section{INTRODUCTION}

D UE to the widespread use of non-linear loads, mains voltage distortion has become an important concern for electric utilities [1]. Harmonic currents and voltages can cause many unfavourable effects on the power system itself and the connected loads. Malfunctioning of electronic equipment, capacitor failure, transformer and neutral conductor overheating, excessive heating in rotating machinery are some of these effects [2].

Especially if there is a harmonic resonance between the power-factor correction capacitors and the transformer and/or cable inductance, there may be a significant amplification of voltage harmonics in the power system [3].

In the last two decades, power quality improvement has become an important target for the product developer and the energy provider. To meet the existing standards, one can install passive or active filters. It was proved that active filters are very effective to compensate harmonic currents and voltages [4]. As compared to passive filters, they do not have problems as resonance generation, component tuning and network impedance dependence. However, they are still very expensive. Therefore, active filters are only installed near large industrial plants.

It was suggested by Akagi [5] that shunt active filters, behaving as linear resistive impedances for harmonics, could be

The authors are with the Department of Electrical Energy, Systems and Automation (EESA), Electrical Energy Laboratory (EELAB), Ghent University, Sint-Pietersnieuwstraat 41, B-9000 Ghent, Belgium (e-mail: Wouter.Ryckaert@ieee.org). spread throughout the power system to reduce the propagation of harmonic pollution. Although complete compensation is only possible using true active filters, shunt harmonic resistances have been shown to provide a considerable reduction of the harmonic propagation. The advantage of this approach is the simplicity of the compensator devices because there is no need for the measurement of the polluting currents [6]. There is also an improved stability margin as compared to active filters compensating for measured current pollution.

This resistive impedance function can be realised as a secondary control function of power electronic energy supplies [7]. Because the simplicity of this control strategy, many power electronic loads can be equipped with it and can be spread throughout the distribution system. In this way, every optimised load has a contribution to the reduction of the harmonic pollution which is very important in the case of resonance conditions.

In this paper, it will be investigated whether it is sufficient to realise the resistive behaviour for a limited number of harmonics (e.g. strongest harmonic voltage component or only harmonics around the power system resonance frequency), and what would be the required resistance value and corresponding current rating of the shunt harmonic impedance (SHI). Also the influence of the background distortion on the required load behaviour of the SHI is considered.

The calculations are performed in the presence of a realistic non-linear load (a single-phase peak rectifier), instead of the more common harmonic current source modelling approach. This is required to obtain reasonable accuracy, as it is well known that the behaviour of such non-linear devices is quite sensitive to changes in the mains voltage waveform and that there is an important interaction between harmonics [8], [9], [10].

\section{Shunt Harmonic ImPedances}

\section{A. System Description}

In Fig. 1 the equivalent circuit of a simple electric power system is shown. The mains voltage source is represented by its no-load voltage $E_{m}(h)$ and its internal mains impedance $Z_{m}(h)$. The mains impedance is usually dominated by the short-circuit impedance of the distribution transformer and the impedance of the connecting busbars and cables and is therefore resistive-inductive. The polluting load is a capacitively smoothed rectifier. The rectifier filter impedance $Z_{N L}$ may 
serve to model both the actual filter impedance of the rectifier and/or the local power impedance (e.g. caused by the cables). replacements

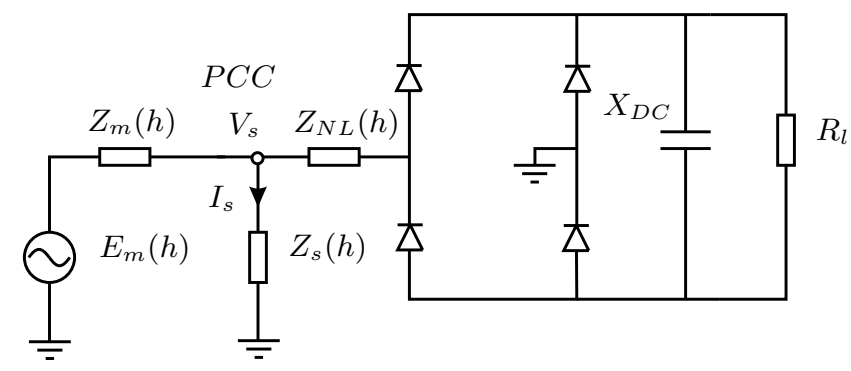

Fig. 1. Simple electric power system (without resonance(s)) containing a shunt harmonic impedance

The following parameters, referred to the apparent power of the distribution transformer $\left(=S_{\text {ref }}\right)$, were used: the mains impedance magnitude $\left|Z_{m}(1)\right|$ equals $0.06 \mathrm{pu}$, its angle equals $\frac{\pi}{4}$; the filter impedance of the rectifier has a magnitude of $\left|Z_{N L}(1)\right|=0.02 p u$ and its argument is $\frac{\pi}{4} ; X_{D C}(1)=0.12 p u$ and $R_{l}$ is adjusted to obtain an active power load of $P=\frac{S_{r e f}}{2}$. The value for $X_{D C}$ is typical for an ICT load.

A shunt harmonic impedance $Z_{s}(h)$ is connected in parallel with the polluting load.

\section{B. Resistive Shunt Harmonic Impedances}

To assess the mitigation potential of the shunt harmonic impedance, the electric power system of Fig. 1 is simulated, using a true resistive impedance $Z_{s}(h)=R_{s}$ for all harmonics, except the fundamental $\left(Z_{s}(1)=\infty\right)$.

The results are summarised in Table I. The THD of the voltage $V_{s}$ at the Point of Common Coupling (PCC) for different values of $Z_{s}(h)$ is compared with the situation without a shunt harmonic impedance (i.e. $Z_{s}(h)=\infty$ ). The RMS value of the current through the shunt impedance $I_{s}$ is also mentioned because it determines the VA-rating, thus the cost of the shunt impedance.

TABLE I

PCC VOLTAGE THD AND RMS VALUES OF $I_{s}$ FOR A TRUE RESISTIVE SHUNT HARMONIC IMPEDANCE

\begin{tabular}{|c|c|c|c|c|}
\hline \hline$R_{s}(p u)$ & $\begin{array}{c}\text { THD } \\
\text { @ PCC }\end{array}$ & $\begin{array}{c}\text { Change } \\
\text { TH }\end{array}$ & $I_{s}($ RMS $)$ & $\begin{array}{c}\text { Rating } \\
I_{s}\end{array}$ \\
\hline \hline$\infty$ & 7.57 & $0.00 \%$ & 0 & $0 \%$ \\
3 & 7.43 & $-1.85 \%$ & 0.0201 & $35 \%$ \\
1 & 7.10 & $-6.21 \%$ & 0.0576 & $100 \%$ \\
0.5 & 6.58 & $-13.08 \%$ & 0.1068 & $185 \%$ \\
0.4 & 6.35 & $-16.11 \%$ & 0.1287 & $223 \%$ \\
0.3 & 5.99 & $-20.8 \%$ & 0.1619 & $281 \%$ \\
0.2 & 5.34 & $-29.5 \%$ & 0.2166 & $376 \%$ \\
0.1 & 3.96 & $-47.7 \%$ & 0.3220 & $559 \%$ \\
\hline
\end{tabular}

From Table I, it can be concluded that the required harmonic impedance magnitude for a noticeable THD reduction is in the order of $1 \mathrm{pu}$ or lower. It has to be mentioned that the application of very low harmonic impedance values may not advisable in the case of mains voltage pollution because this may cause large harmonic line currents to flow, see Section III.

When there are resonances in the power system, we will see a more pronounced voltage THD reduction for the same values of the resistive SHI (Section IV). In addition, it has to be mentioned that power quality problems concerning harmonics, mostly occur when there are power system resonances.

\section{A Single Harmonic Impedance}

We may wonder if the same or lower PCC voltage THD (as compared with an 1 pu resistive impedance $\forall h$ ) can be achieved by tackling the strongest harmonic component. To investigate this, only one harmonic component will be influenced by the shunt harmonic impedance (instead of all harmonics in II-B). In general, the shunt harmonic impedance is not restricted to a resistance, the whole plane of impedances will be considered.

The voltage THD at the PCC and the RMS current drawn by $Z_{s}(h)$ are calculated for different shunt harmonic impedances $Z_{s}(h)$ (i.e. an impedance only drawing current of order $h$, and therefore representing $\left|Z_{s}(h)\right|=\infty$ for all other harmonics).

The results are summarised in Table II. The RMS current drawn by a true resistive impedance of 1 pu (Table I) is taken as the reference value to compare the rating of different shunt impedances. The PCC voltage THD when no impedance is connected, is the reference for the PCC voltage THD.

With a third harmonic impedance $Z_{s}(h)=Z_{s}(3)$, the minimum value of $T H D_{V}$ is $5.83 \%$ with a RMS current through the shunt impedance of $503 \%$. Nearly the same THD value $(5.99 \%)$ is achieved with a $0.3 \mathrm{pu}$ true resistive impedance for all harmonics, but with a much lower RMS current $(281 \%)$, see Table I.

The THD value of $7.10 \%$ for a 1 pu resistive harmonic impedance (Table I), can be reached by a third harmonic impedance with a slightly lower current value of $86 \%$.

See Table II for the influence of the 5th and 9th harmonic impedance.

Concluding, influencing only one harmonic is not (or not much) better than placing a true resistive harmonic impedance.

\section{1 pu Resistive Impedances $\forall h$, except one}

Again, the system of Fig. 1 is simulated and the voltage THD at the PCC and the RMS current drawn by $Z_{s}(h)$ are calculated for different shunt harmonic impedances $Z_{s}(h)$. Now, $Z_{s}(h)$ exists of an impedance drawing current of order $h_{s}$ in parallel with an $1 \mathrm{pu}$ resistive impedance for all other harmonics $\neq h_{s}$, of course $Z_{s}(1)=\infty$ remains (Fig. 2).

The results are summarised in Table III, with the same reference values as in section II-C.

The minimum PCC voltage THD value is $5.4 \%$ for a varying third harmonic impedance ( $1 \mathrm{pu}$ resistive, for all other harmonics), with an RMS current of $508 \%$. The value of $Z_{s}(3)$ is $0.03+0.001 \mathrm{i}$. The same THD value can be achieved with a true resistive impedance of $0.2 \mathrm{pu}$, drawing a lower RMS current of $376 \%$. The THD value of $7.10 \%$ for a $1 \mathrm{pu}$ resistive harmonic impedance (Table I) can be reached with a slightly lower current value of $85 \%$. 
TABLE II

INFLUENCE OF A SINGLE HARMONIC IMPEDANCE ON THE PCC VOLTAGE THD AND RMS VALUES OF $I_{s}$

\begin{tabular}{|l|c|c|c|c|c|c|}
\hline \hline $\begin{array}{l}\text { Harmonic } \\
\text { Impedance }\end{array}$ & $\begin{array}{c}\text { THD } \\
\text { @ PCC }\end{array}$ & $\begin{array}{c}\text { Change } \\
\text { TH } D_{V}\end{array}$ & $I_{s}(R M S)$ & Rating & $Z_{s}(h)$ & $\left|Z_{s}(h)\right|$ \\
\hline \hline$Z_{s}(h)=\infty \forall h$ & 7.57 & $0 \%$ & 0 & $0 \%$ & $\infty$ & $\infty$ \\
\hline$R=1 p u$ & 7.10 & $-6.21 \%$ & 0.0201 & $100 \%$ & $1.00+0.00 \mathrm{i}$ & 1.00 \\
\hline$Z_{s}(3) @ \min . T H D_{V}$ & 5.83 & $-22.98 \%$ & 0.2899 & $503 \%$ & $0.04+0.00 \mathrm{i}$ & 0.04 \\
$Z_{s}(3) @ T H D_{V}, @ R=1 p u$ & 7.08 & $-6.2 \%$ & 0.04985 & $86 \%$ & $0.36+0.67 \mathrm{i}$ & 0.76 \\
\hline$Z_{s}(5) @ \min . T H D_{V}$ & 6.81 & $-10.03 \%$ & 0.1541 & $268 \%$ & $0.08+0.02 \mathrm{i}$ & 0.08 \\
$Z_{s}(5) @ T H D_{V}, @ R=1 p u$ & 7.08 & $-6.2 \%$ & 0.0636 & $110 \%$ & $0.28+0.26 \mathrm{i}$ & 0.38 \\
\hline$Z_{s}(9) @ \min . T H D_{V}$ & 7.29 & $-3.7 \%$ & 0.0495 & $86 \%$ & $0.08-0.03 \mathrm{i}$ & 0.09 \\
\hline
\end{tabular}

TABLE III

INFLUENCE OF A HARMONIC IMPEDANCE ON THE PCC VOLTAGE THD AND RMS VALUES OF $I_{s}$ WHEN THE IMPEDANCE FOR OTHER HARMONICS IS RESISTIVE (1 PU)

\begin{tabular}{|l|c|c|c|c|c|c|}
\hline \hline $\begin{array}{l}\text { Harmonic } \\
\text { Impedance }\end{array}$ & $\begin{array}{c}T H D_{V}(\%) \\
\text { PCC }\end{array}$ & $\begin{array}{c}\text { Change } \\
T H D_{V}\end{array}$ & $I_{s}(R M S)$ & Rating & $Z_{s}(h)$ & $\left|Z_{s}(h)\right|$ \\
\hline \hline$Z_{s}(h)=\infty \forall h$ & 7.57 & $0 \%$ & 0 & $0 \%$ & $\infty$ & $\infty$ \\
\hline$R=1 p u$ & 7.10 & $-6.21 \%$ & 0.0201 & $100 \%$ & $1.00+0.00 \mathrm{i}$ & 1.00 \\
\hline$Z_{s}(3) @ \min . T H D_{V}$ & 5.40 & $-28.67 \%$ & 0.2930 & $508 \%$ & $0.03+0.01 \mathrm{i}$ & 0.03 \\
$Z_{s}(3) @ T H D_{V}, @ R=1 p u$ & 7.02 & $-7.3 \%$ & 0.0490 & $85 \%$ & $0.59+1.31 \mathrm{i}$ & 1.44 \\
\hline$Z_{s}(5) @ \min . T H D_{V}$ & 6.42 & $-15.19 \%$ & 0.1623 & $282 \%$ & $0.06+0.04 \mathrm{i}$ & 0.071 \\
$Z_{s}(5) @ T H D_{V}, @ R=1 p u$ & 7.10 & $-6.21 \%$ & 0.0527 & $91 \%$ & $1.23+0.82 \mathrm{i}$ & 1.48 \\
\hline$Z_{s}(9) @ \min . T H D_{V}$ & 6.84 & $-9.64 \%$ & 0.0792 & $138 \%$ & $0.05-0.05 \mathrm{i}$ & 0.07 \\
$Z_{s}(9) @ @ T H D_{V}, @ R=1 p u$ & 7.10 & $-6.21 \%$ & 0.0570 & $99 \%$ & always & always \\
\hline
\end{tabular}

PSfrag replacements

eplacements

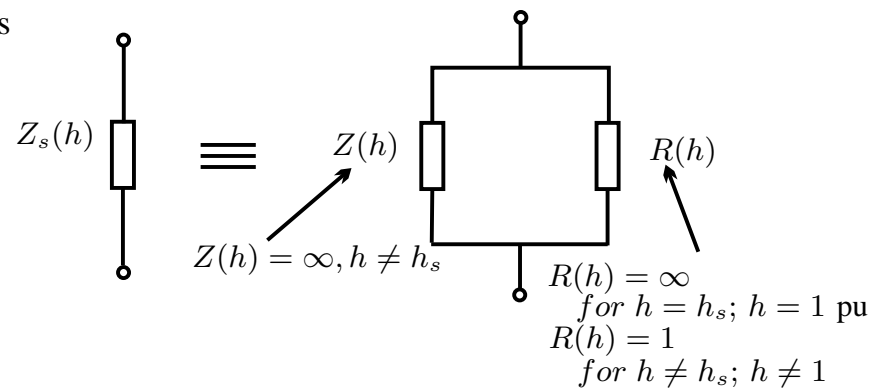

Fig. 2. Shunt harmonic impedance

Again, it can be concluded that a true resistive harmonic impedance for all harmonics is a good option if the RMS current of the shunt impedance is taken into account.

\section{LIMITING THE INFLUENCE OF BACKGROUND DISTORTION [7]}

\section{A. Limiting the harmonic line current}

The influence of the background distortion and the resulting necessity to limit the minimum impedance of the SHI is explained. For this purpose, it is assumed that the polluting loads can be modelled as simple current sources. The remaining power system is supposed to be linear and is represented in a very simplified form as in Fig. 3. The Thévenin equivalent of the power system voltage for the harmonic of order $h$ is represented by the voltage source $E_{m}(h)$ and internal impedance $Z_{m}(h)$. The impedance $Z_{p}(h)$ represents

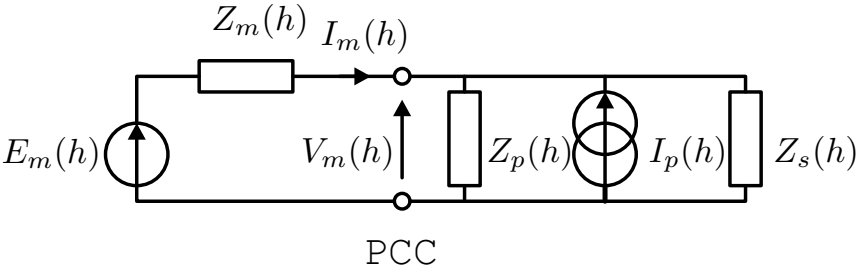

Fig. 3. Example: simple power system

the harmonic impedance of the linear loads connected at the Point of Common Coupling (PCC). The current source $I_{p}(h)$ represents the polluting loads connected to the $\mathrm{PCC}$, and $Z_{s}(h)$ is the pursued shunt harmonic impedance.

Suppose the power system voltage is polluted with background distortion $\left(E_{m}(h) \neq 0\right.$ in Fig. 3). When $Z_{s}(h)$ is not connected and no polluting loads are present, the harmonic line current $\left|I_{m 0}(h)\right|$ due to background distortion becomes:

$$
\left|I_{m 0}(h)\right|=\left|\frac{E_{m}(h)}{Z_{m}(h)+Z_{p}(h)}\right|
$$

On order for $Z_{s}(h)$ to limit the harmonic line current, the following condition should be satisfied:

$$
\left|I_{m}(h)\right|=\left|\frac{E_{m}(h)}{Z_{m}(h)+\frac{Z_{p}(h) Z_{s}(h)}{Z_{p}(h)+Z_{s}(h)}}\right|<I_{m, \max }(h)
$$

The evaluation of this condition requires the definition of the maximum values $I_{m, \max }(h)$. Depending on the parameters 
$E_{m}(h), Z_{m}(h)$ and $Z_{p}(h)$, the favourable values of $Z_{s}(h)$ fulfilling requirement (2) can be calculated. In practice, these parameters can vary widely and may not even be known.

Moreover, when $Z_{p}(h)$ varies within a given distribution (e.g. because of load variations, or because $Z_{p}(h)$ is not exactly known), the area of favourable values of $Z_{s}(h)$ satisfying (2) for all occurring values of $Z_{p}(h)$ may be very small or may even not exist.

Also, it can hardly be argued that the responsibility to limit the harmonic line currents due to background distortion relies solely on the pursued favourable load, i.e. that $Z_{s}(h)$ should compensate for $Z_{p}(h)$ causing excessive harmonic line currents $\left|I_{m 0}(h)\right|>I_{m, \max }(h)$ (1). Concluding, condition (2) seems inappropriate for the purpose.

\section{B. Imposing a minimum load impedance}

A more practical criterion to limit the influence of background distortion would be to limit the impedance in the denominator of (2), without considering the presence of the other linear loads (i.e. $Z_{p}(h)=\infty$ ):

$$
\left|Z_{m}(h)+Z_{s}(h)\right|>Z_{\min }
$$

In this way, the favourable values for $Z_{s}(h)$ to satisfy (3) become independent of the power system pollution $E_{m}(h)$. Moreover, the responsibility of limiting the harmonic line currents due to background distortion is not solely relying on the pursued favourable load, except when no other linear loads $Z_{p}(h)$ are present. In practice, well-chosen values for $Z_{\text {min }}$ would be in the order of magnitude of $0.5-1 \mathrm{pu}$, leading to per-unit harmonic current levels limited to maximum two times the order of magnitude of the per-unit harmonic voltage levels:

$$
\left|I_{m}(h)\right|=\left|\frac{E_{m}(h)}{Z_{m}(h)+Z_{s}(h)}\right|<\frac{\left|E_{m}(h)\right|}{Z_{\text {min }}}
$$

It is easily verified that the locus of the favourable values for $Z_{s}(h)$ (3) lies outside the circle with origin $c_{I}$ and radius $r_{I}$ :

$$
\begin{aligned}
c_{I} & =-Z_{m}(h) \\
r_{I} & =Z_{\min }
\end{aligned}
$$

\section{Example: limiting the harmonic line current due to back- ground distortion}

As an example, consider the following power system impedance:

$$
Z_{m}(h)=0.042+j 0.042 h \mathrm{pu}
$$

In Fig. 4 the favourable values of $Z_{s}(11)$ are shown, for different values of $Z_{\text {min }}$ (and $Z_{p}(h)=\infty$ ). It shows that the locus of the favourable values grows with decreasing $Z_{\text {min }}$. The unfavourable values are concentrated around the capacitive impedance causing resonance with the inductive mains impedance. As can be deduced from Fig. 3 with $Z_{p}(h)=\infty$, this case represents a series resonance for the voltage source $E_{m}(h)$, leading to a low impedance $\left|Z_{m}(h)+Z_{s}(h)\right|$ and consequently leading to high harmonic line current magnitudes $\left|I_{m}(h)\right|$.

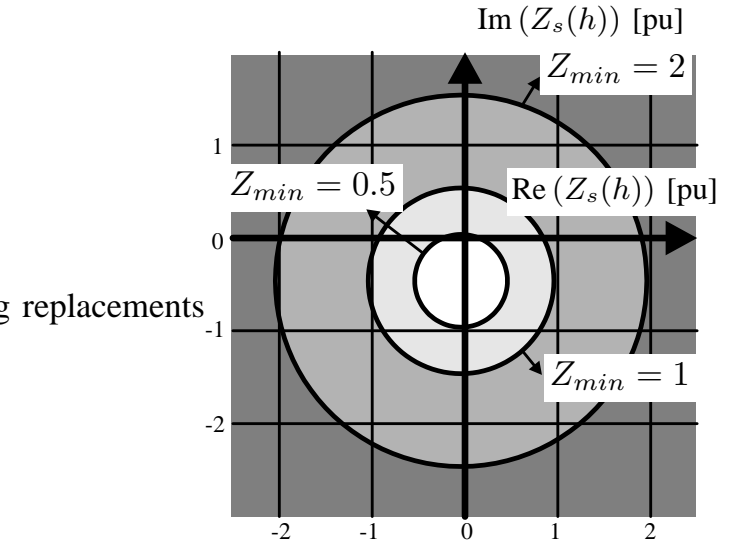

Fig. 4. Favourable values for $Z_{s}(11)$ to limit the harmonic currents due to background voltage distortion, $Z_{\min }=0.5 \ldots 2 \mathrm{pu}$

\section{Resistive shunt harmonic impedances and background dis- tortion}

In particular, we can determine the minimum impedance of a resistive SHI to limit the harmonic line currents due to background distortion. The results are summarized in Table IV for different values of $Z_{\min }$ and $Z_{m}(h)$. We suppose that the power system impedance is purely inductive $Z_{m}(h)=$ j.h. $\left|Z_{m}(1)\right|$, which is a good approximation for harmonics. To limit the per-unit harmonic current levels to maximum two times the per-unit harmonic voltage levels (i.e. $Z_{\min }=$ $0.5 \mathrm{pu}$ ), it follows from Table IV that the required minimum resistive impedance $Z_{s}(h)=R_{s}$ for lower order harmonics is $0.49 \mathrm{pu}$ for small transformers (typical used in LV distribution power systems) and $0.40 \mathrm{pu}$ for greater transformers, which are normally used in MV distribution power systems.

For higher order harmonics, the minimum impedance may be lower because the transformer impedance $Z_{m}$ becomes dominant. If the harmonic current levels have to be limited to the order of magnitude of the harmonic voltage (e.g. when the voltage distortion is high), the required minimum impedance increases to about $1 \mathrm{pu}$.

\section{Shunt HaRmonic IMPEDAnCES AND ResonanCE}

\section{A. System Description}

The system of Fig. 1 is extended with a capacitor $X_{C}$ (Fig. 5). This capacitor, e.g. used for power factor correction, is tuned to obtain resonance at the 11th harmonic. The capacitor generates $0.195 \mathrm{pu}$ of reactive power and its resistive loss is modelled as a parallel resistance $R_{C}$ drawing $0.0195 \mathrm{pu}$ of active power.

The other parameters are as above: $\left|Z_{m}(1)\right|=0.06 \mathrm{pu}$, $\angle Z_{m}(1)=\frac{\pi}{4},\left|Z_{N L}(1)\right|=0.02 \mathrm{pu}, \angle Z_{N L}(1)=\frac{\pi}{4}$, $X_{D C}(1)=0.12 p u$ and $R_{l}$ is adjusted to obtain an active power load of $P=\frac{S_{r e f}}{2}$.

\section{B. Resistive Shunt Harmonic Impedances}

As in II-B, the mitigation potential of true resistive impedance $Z_{s}(h)=R_{s}$ is investigated (Table V). It follows that resistive shunt impedances are attractive to damp the 
TABLE IV

MINIMUM VALUE FOR A RESISTIVE SHI TO LIMIT THE INFLUENCE OF BACKGROUND DISTORTION

\begin{tabular}{|c|c|c||c|c|c||c|c|c|}
\hline \hline $\begin{array}{c}Z_{\min } \\
=1 \mathrm{pu}\end{array}$ & $\begin{array}{c}\left|Z_{m}(1)\right| \\
=0.10 \mathrm{pu}\end{array}$ & $\begin{array}{c}\left|Z_{m}(1)\right| \\
=0.04 \mathrm{pu}\end{array}$ & $\begin{array}{c}Z_{\min } \\
=0.66 \mathrm{pu}\end{array}$ & $\begin{array}{c}\left|Z_{m}(1)\right| \\
=0.10 \mathrm{pu}\end{array}$ & $\begin{array}{c}\left|Z_{m}(1)\right| \\
=0.04 \mathrm{pu}\end{array}$ & $\begin{array}{c}Z_{\min } \\
=0.5 \mathrm{pu}\end{array}$ & $\begin{array}{c}\left|Z_{m}(1)\right| \\
=0.10 \mathrm{pu}\end{array}$ & $\begin{array}{c}\left|Z_{m}(1)\right| \\
=0.04 \mathrm{pu}\end{array}$ \\
\hline \hline $\mathrm{h}=3$ & 0.95 & 0.99 & $\mathrm{~h}=3$ & 0.69 & 0.74 & $\mathrm{~h}=3$ & 0.40 & 0.49 \\
$\mathrm{~h}=5$ & 0.87 & 0.98 & $\mathrm{~h}=5$ & 0.56 & 0.72 & $\mathrm{~h}=5$ & 0 & 0.46 \\
$\mathrm{~h}=7$ & 0.71 & 0.96 & $\mathrm{~h}=7$ & 0.27 & 0.70 & $\mathrm{~h}=7$ & 0 & 0.41 \\
$\mathrm{~h}=9$ & 0.44 & 0.93 & $\mathrm{~h}=9$ & 0 & 0.66 & $\mathrm{~h}=9$ & 0 & 0.35 \\
$\mathrm{~h}=11$ & 0 & 0.90 & $\mathrm{~h}=11$ & 0 & 0.61 & $\mathrm{~h}=11$ & 0 & 0.24 \\
$\mathrm{~h}=13$ & 0 & 0.85 & $\mathrm{~h}=13$ & 0 & 0.54 & $\mathrm{~h}=13$ & 0 & 0 \\
$\mathrm{~h}=15$ & 0 & 0.80 & $\mathrm{~h}=15$ & 0 & 0.45 & $\mathrm{~h}=15$ & 0 & 0 \\
\hline
\end{tabular}

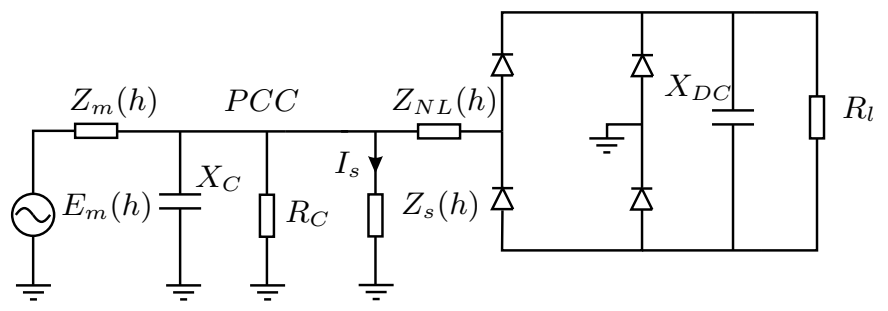

Fig. 5. Simple electric power system (with resonance(s)) containing a shunt harmonic impedance

TABLE V

PCC VOLTAGE THD AND RMS VALUES OF $I_{s}$ FOR A TRUE RESISTIVE SHUNT HARMONIC IMPEDANCE (SYSTEM WITH RESONANCE)

\begin{tabular}{|c|c|c|c|c|}
\hline \hline$R_{s}(p u)$ & $\begin{array}{c}T H D_{V}(\%) \\
@ \text { PCC }\end{array}$ & $\begin{array}{c}\text { Change } \\
T H D_{V}\end{array}$ & $I_{s}(R M S)$ & $\begin{array}{c}\text { Rating } \\
I_{s}\end{array}$ \\
\hline \hline$\infty$ & 11.42 & Ref. & 0 & $0 \%$ \\
3 & 9.58 & $-16.1 \%$ & 0.0261 & $39 \%$ \\
1 & 8.14 & $-28.7 \%$ & 0.0665 & $100 \%$ \\
0.5 & 7.12 & $-37.7 \%$ & 0.1164 & $175 \%$ \\
0.4 & 6.77 & $-40.7 \%$ & 0.1383 & $208 \%$ \\
0.3 & 6.28 & $-45.0 \%$ & 0.1713 & $258 \%$ \\
0.2 & 5.50 & $-51.8 \%$ & 0.2252 & $339 \%$ \\
0.1 & 4.01 & $-64.9 \%$ & 0.3279 & $493 \%$ \\
\hline
\end{tabular}

resonance, certainly for values between $0.5 \mathrm{pu}$ and $1 \mathrm{pu}$ as the resulting $T H D_{V}$ value is reduced to about the value of the system without resonance and $Z_{s}(h)=\infty$ (Table I). Lower values of $R_{s}$ are not encouraged to prohibit excessive harmonic line currents when the mains voltage is polluted (Section III).

The effect of a $1 \mathrm{pu}$ harmonic resistance on the voltage harmonic spectrum is illustrated in Fig. 6. At resonance conditions, the magnitude $\left|Z_{\text {tot }}(h)\right|$ of the power system impedance at the PCC becomes much higher than the magnitude $\left|Z_{m}(h)\right|$ of the no-load power system impedance. For this example, resonance occurs for $h=11$, and $\left|Z_{\text {tot }}(11)\right|=4.66 \mathrm{pu}$, which is 7 times higher than the value for $\left|Z_{m}(11)\right|$ (=0.66 pu). $\left|Z_{m}(h)\right|=h\left|Z_{m}(1)\right|$ can be considered as the 'natural' magnitude of the power system impedance [11]. Consequently, the rectifier harmonic currents near the resonance frequency cause considerable voltage distortion (solid line in Fig. 6). The harmonic power system impedance at the PCC is limited by connection of the shunt harmonic resistance, certainly for frequencies around the resonance. This explains why mainly the harmonic voltage components around the resonance are reduced (dashed line in Fig. 6).

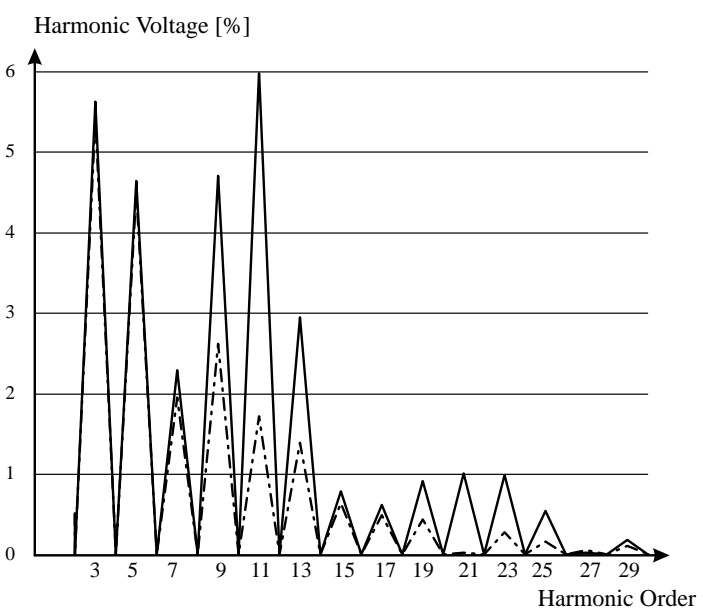

Fig. 6. PCC voltage spectrum for $Z s(h)=R_{s}=1 p u$ (dashed line) and for $Z_{s}(h)=\infty$ (solid line)

\section{A Single Harmonic Impedance}

To damp the harmonic propagation, the use of a single harmonic impedance is investigated, i.e. an impedance drawing current of only one harmonic order. As compared with a resistive harmonic impedance for all harmonics, it can be concluded from Table VI that the PCC-voltage THD is not extremely reduced by influencing a single harmonic component. Some additional considerations:

- In the case of a resonance, creating a short-circuit for the strongest or one of the strongest harmonic components is not (always) a good solution. Figure 7 shows that, in this specific case, the PCC voltage THD slightly deteriorates when the 5th harmonic component is short circuited $\left(\operatorname{Re}\left(Z_{s}(5)\right)=\operatorname{Im}\left(Z_{s}(5)\right)=0\right)$. The reason is that other harmonic voltage components are amplified through the commutation behaviour of the rectifier and through the remaining resonance(s). This is illustrated in Fig. 8, where the 5th harmonic component is 0 but other components are amplified.

Favourable values of $Z_{s}(h)=Z_{s}(5)$ are rather resistivecapacitive (Fig. 7). The minimum THD value which can 
TABLE VI

INFLUENCE OF A SINGLE HARMONIC IMPEDANCE ON THE PCC VOLTAGE THD AND RMS VALUES OF $I_{s}$ (SYSTEM WITH RESONANCE)

\begin{tabular}{|l|c|c|c|c|c|c|}
\hline \hline $\begin{array}{l}\text { Harmonic } \\
\text { Impedance }\end{array}$ & $\begin{array}{c}\text { TH } D_{V}(\%) \\
\text { @ PCC }\end{array}$ & $\begin{array}{c}\text { Change } \\
T H D_{V}\end{array}$ & $I_{s}(R M S)$ & $\begin{array}{c}\text { Rating } \\
I_{s}\end{array}$ & $Z_{s}(h)$ & $\left|Z_{s}(h)\right|$ \\
\hline \hline$Z_{s}(h)=\infty \forall h$ & 11.42 & $0 \%$ & 0 & $0 \%$ & $\infty$ & $\infty$ \\
\hline$R=1 p u$ & 8.14 & $-28.7 \%$ & 0.0665 & $100 \%$ & $1.00+0.00 \mathrm{i}$ & 1.00 \\
\hline$Z_{s}(3) @ \min . T H D_{V}$ & 9.89 & $-13.4 \%$ & 0.3069 & $462 \%$ & $0.08+0.06 \mathrm{i}$ & 0.1 \\
\hline$Z_{s}(5) @ \min . T H D_{V}$ & 9.49 & $-16.9 \%$ & 0.1966 & $296 \%$ & $0.11-0.18 \mathrm{i}$ & 0.21 \\
\hline$Z_{s}(9) @ \min . T H D_{V}$ & 9.33 & $-18.3 \%$ & 0.0566 & $85 \%$ & $0.20-0.37 \mathrm{i}$ & 0.42 \\
\hline$Z_{s}(11) @ \min . T H D_{V}$ & 9.85 & $-13.7 \%$ & 0.0354 & $53 \%$ & $0.38+0.47 \mathrm{i}$ & 0.60 \\
\hline$Z_{s}(13) @ \min . T H D_{V}$ & 10.64 & $-6.83 \%$ & 0.0283 & $42 \%$ & $0.47+0.56 \mathrm{i}$ & 0.73 \\
\hline
\end{tabular}

be achieved with a 5 th harmonic shunt impedance is $9.49 \%$ with $Z_{s}(5)=0.11-0.18 i \mathrm{pu}$ and an RMS rating of $296 \%$. The harmonic decomposition of the PCC voltage for minimum THD with $Z_{s}(5)$ is shown in Fig. 9. It is remarkable that the 5th harmonic component frag replacementflightly rises, but that the resonance is damped. To obtain the same THD value with a true resistive impedance for all harmonics, only a $3 \mathrm{pu}$ resistance is needed. This resistance draws 7.5 times less RMS current than the 5th harmonic impedance (see Table V).

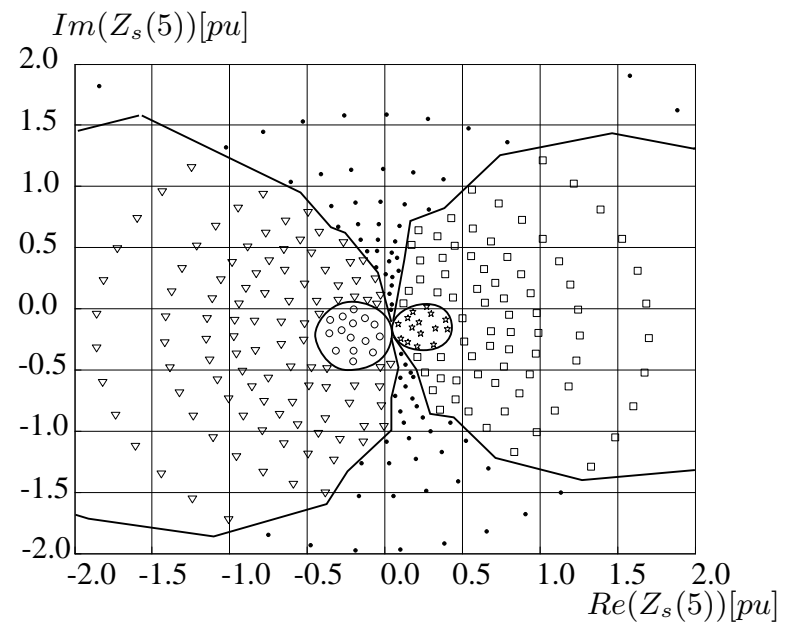

Fig. 7. PCC voltage THD increase for different values of $Z_{s}(5): 0:>1.2$, $\nabla: 1.02 \ldots 1.2, \bullet: 0.98 \ldots 1.02, \square: 0.9 \ldots 0.98, \star:<0.9$

- An other solution could be to detect the resonance and installing a harmonic impedance, only drawing current for the resonance frequency. Unfortunately, this seems not a good solution (Table VI, $Z_{s}(11)$ ) because other harmonic components close to the resonance remain high after installing the SHI. Therefore, the resonance is not well damped and the THD is not reduced much. This is shown in Fig. 10, where the PCC voltage spectrum at minimum THD with an impedance $Z_{s}(h)=Z_{s}(11)$ is drawn together with the voltage spectrum when $Z_{s}(h)=$ $\infty$. Placing an impedance which draws current for several harmonic components, is needed to damp the resonance.

- Therefore, one could place an impedance drawing current of order $h=h_{R E S}$ and of order $h=h_{R E S} \pm 2$
Harmonic Voltage [\%]

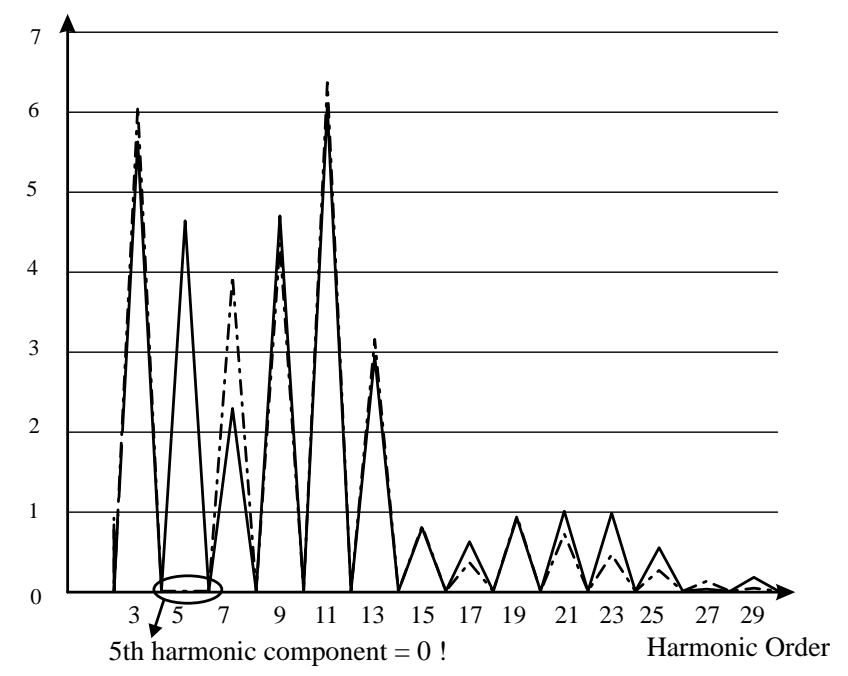

Fig. 8. PCC voltage spectrum for $Z_{s}(h)=Z_{s}(5)=0$ (dashed line) and for $Z_{s}(h)=\infty$ (solid line)

to damp the resonance at harmonic order $h=h_{R E S}$. The PCC voltage THD and the RMS current through the shunt impedance are summarised in Table VII. The shunt impedance is resistive for the 9th, 11th and 13th harmonic voltage components and is an open-circuit for all other harmonic orders. With a 1 pu resistance for the 9th, 11th and 13th components, the voltage THD is reduced with $22 \%$, with an RMS current through $Z_{s}(h)$ of $0.0336 \mathrm{~A}$, which is $50 \%$ of the RMS current of a $1 \mathrm{pu}$ resistive harmonic impedance for all harmonics. However, the THD value of $8.14 \%$ (Table $\mathrm{V}$ ) for a 1 pu resistive harmonic impedance can not be reached with a resistance for only 3 harmonic voltage components $\left(h=h_{R E S}\right.$ and $\left.h=h_{R E S} \pm 2\right)$. Fig. 11 shows the PCC voltage spectrum for a shunt impedance $Z_{s 9,11,13}=R=0.1 \mathrm{pu}$, together with the spectrum when $Z_{s}(h)=\infty$. The favourable effect of the shunt impedance on the 9th, 11th en 13th voltage component is striking. However, some other harmonic components rise considerably (e.g. 4 times for the 15 th harmonic). This is explained by the commutation behaviour of the rectifier. This effect, together with the fact that the highest harmonic components (3th and 5th) are still high, explains that the THD values are not 


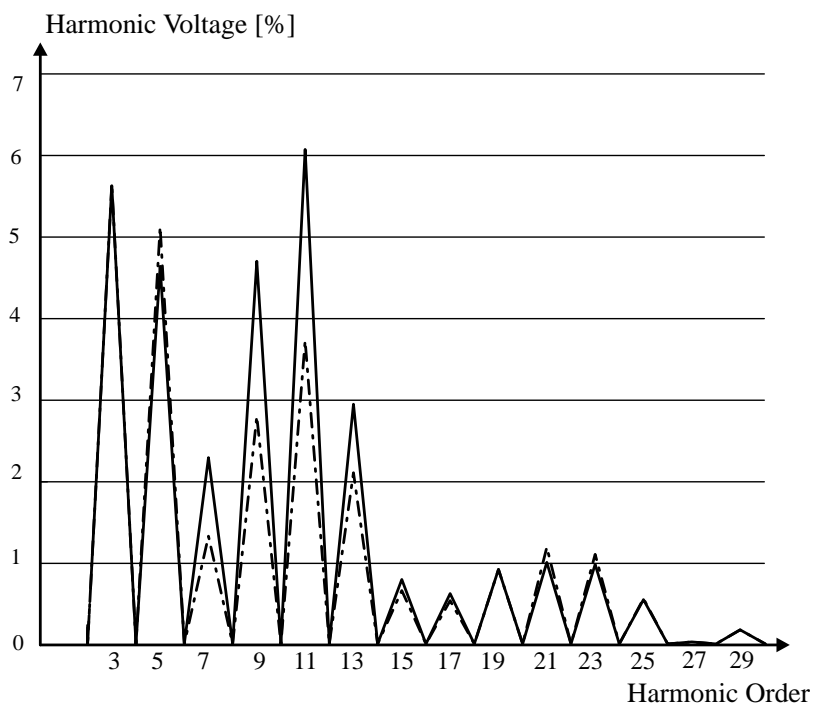

Fig. 9. PCC voltage spectrum for minimum THD with $Z_{s}(5)$ (dashed line) and for $Z_{s}(h)=\infty$ (solid line)

Harmonic Voltage [\%]

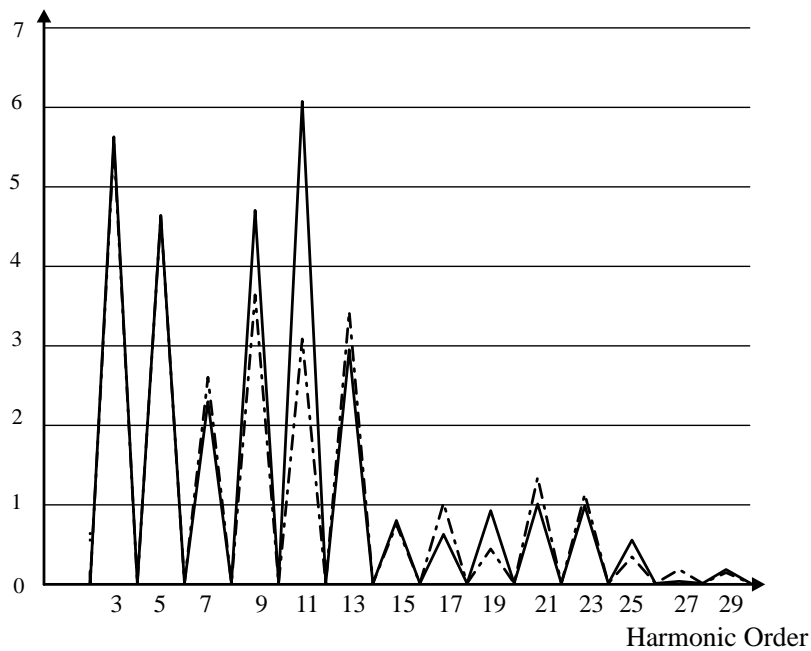

Fig. 10. PCC voltage spectrum for minimum THD with $Z_{s}(11)$ (dashed line) and for $Z_{s}(h)=\infty$ (solid line)

reduced much with lower resistive values.

\section{1 pu Resistive Impedances $\forall$, except one}

It is clear from sections IV-B and IV-C that the shunt impedance must act upon all harmonic voltage components to damp harmonic propagation effectively. Now, we investigate the effect of an impedance $Z_{s}(h)$ which exists of an impedance drawing current of order $h$ in parallel with an 1 pu resistive impedance for all other harmonics $\neq h$, except for the fundamental component (Fig. 2). The results are mentioned in Table VIII. Only with a small $Z_{s}(3)$ one can obtain a remarkable improvement of the voltage THD $(6.65 \%)$ as compared to an $1 \mathrm{pu}$ resistance for all harmonics. However, the required RMS current is high $(443 \%)$ and the required impedance for the 3 th harmonic is extremely low $(0.03 \mathrm{pu})$, which is dangerous for a mains voltage polluted with an even
TABLE VII

PCC VOLTAGE THD AND RMS VALUES OF $I_{s}$ FOR A TRUE RESISTIVE SHUNT HARMONIC IMPEDANCE FOR THE 9TH, $11 \mathrm{TH}$ AND 13TH HARMONIC ORDER

\begin{tabular}{|c|c|c|c|c|}
\hline $\begin{array}{c}R_{s 9,11,13} \\
{[p u]}\end{array}$ & $\begin{array}{c}\text { THD } \\
\text { @ PCC }\end{array}$ & $\begin{array}{c}\text { Change } \\
T H D_{V}\end{array}$ & $I_{s}(R M S)$ & $\begin{array}{c}\text { Rating } \\
I_{s}\end{array}$ \\
\hline \hline$\infty$ & $11.42 \%$ & $0 \%$ & 0.00 & $0 \%$ \\
3 & 9.88 & $-13 \%$ & 0.016 & $24 \%$ \\
1 & 8.94 & $-22 \%$ & 0.034 & $51 \%$ \\
0.5 & 8.56 & $-25 \%$ & 0.049 & $74 \%$ \\
0.3 & 8.44 & $-26 \%$ & 0.063 & $97 \%$ \\
0.1 & 8.39 & $-27 \%$ & 0.089 & $134 \%$ \\
\hline
\end{tabular}

Harmonic Voltage [\%]

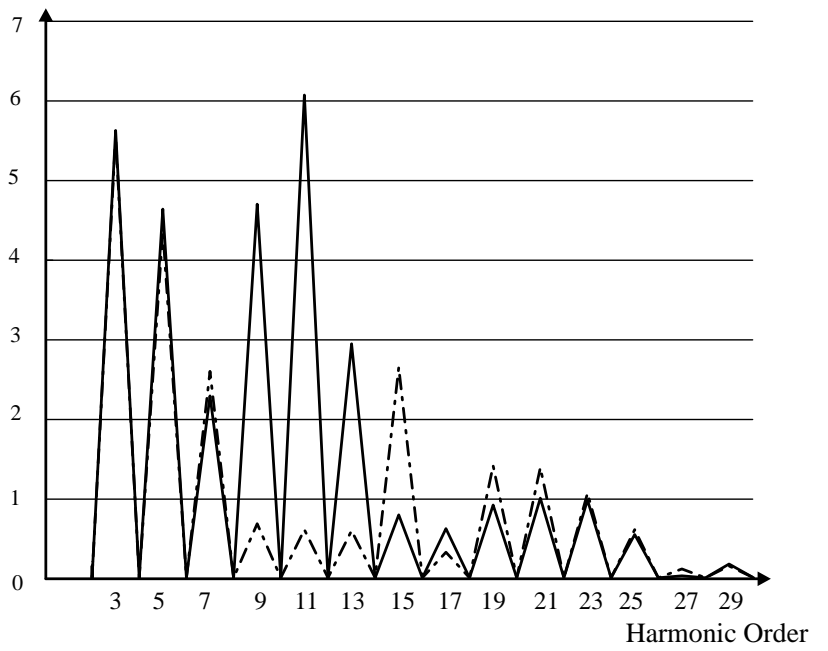

Fig. 11. PCC voltage spectrum when $Z_{s 9,11,13}=R=0.1 p u$ (dashed line) and for $Z_{s}(h)=\infty$ (solid line)

low 3th harmonic component. To obtain the same THD, one could place a 0.4 pu resistive impedance for all harmonics.

\section{CONCLuSions}

Shunt harmonic impedances can reduce the line current and mains voltage THD caused by polluting loads. In this paper, it is shown that SHI are most useful in the case of resonances. To take into account the interaction between harmonics, simulations are performed in the presence of a realistic non-linear load, instead of the more common harmonic current source modelling approach.

To damp the harmonic propagation, it is shown that the preferred SHI is resistive for all harmonics, with a magnitude of about $0.5-1 \mathrm{pu}$ (referred to the apparent power of the distribution transformer). Lower values are not encouraged to prohibit excessive harmonic line currents, especially when the mains voltage is polluted with low order harmonic voltages.

It has been shown that it is not sufficient to realise an impedance for a limited number of harmonics. For instance, tackling the strongest harmonic voltage component, or influencing only the harmonics around the power system resonance frequency, are not as effective because other harmonic components may be amplified. 
TABLE VIII

INFLUENCE OF A HARMONIC IMPEDANCE ON THE PCC VOLTAGE THD AND RMS VALUES OF $I_{s}$ WHEN THE IMPEDANCE FOR OTHER HARMONICS IS RESISTIVE (1 PU) (SYSTEM WITH RESONANCE)

\begin{tabular}{|l|c|c|c|c|c|c|}
\hline \hline $\begin{array}{l}\text { Harmonic } \\
\text { Impedance }\end{array}$ & $\begin{array}{c}T H D_{V}(\%) \\
\text { @ PCC }\end{array}$ & $\begin{array}{c}\text { Change } \\
T H D_{V}\end{array}$ & $I_{s}(R M S)$ & $\begin{array}{c}\text { Rating } \\
I_{s}\end{array}$ & $Z_{s}(h)$ & $\left|Z_{s}(h)\right|$ \\
\hline \hline$Z_{s}(h)=\infty \forall h$ & 11.42 & $0 \%$ & 0 & $0 \%$ & $\infty$ & $\infty$ \\
\hline$R=1 p u \forall h$ & 8.14 & $-28.7 \%$ & 0.0665 & $100 \%$ & $1.00+0.00 \mathrm{i}$ & 1.00 \\
\hline$Z_{s}(3) @ \min . T H D_{V}$ & 6.65 & $-41.8 \%$ & 0.2948 & $443 \%$ & $0.03+0.01 \mathrm{i}$ & 0.03 \\
$Z_{s}(3) @ T H D_{V}, @ R=1 p u$ & 8.12 & $-28.9 \%$ & 0.058 & $87 \%$ & $1.05+1.10 \mathrm{i}$ & 1.52 \\
\hline$Z_{s}(5) @ \min . T H D_{V}$ & 7.27 & $-36.3 \%$ & 0.1643 & $247 \%$ & $0.01-0.01 \mathrm{i}$ & 0.01 \\
$Z_{s}(5) @ T H D_{V}, @ R=1 p u$ & 8.07 & $-29.3 \%$ & 0.066 & $100 \%$ & $0.86+0.47 \mathrm{i}$ & 0.98 \\
\hline$Z_{s}(9) @ \min . T H D_{V}$ & 7.69 & $-32.7 \%$ & 0.0797 & $120 \%$ & $0.13-0.05 \mathrm{i}$ & 0.14 \\
$Z_{s}(9) @ T H D_{V}, @ R=1 p u$ & 8.07 & $-29.3 \%$ & 0.066 & $100 \%$ & $0.87+0.30 \mathrm{i}$ & 0.92 \\
\hline$Z_{s}(11) @ \min . T H D_{V}$ & 7.89 & $-30.9 \%$ & 0.0699 & $105 \%$ & $-0.04+0.30 \mathrm{i}$ & 0.30 \\
$Z_{s}(11) @ T H D_{V}, @ R=1 p u$ & 8.11 & $-29.4 \%$ & 0.065 & $97 \%$ & $-0.29+1.42 \mathrm{i}$ & 1.45 \\
\hline$Z_{s}(13) @ \min . T H D_{V}$ & 7.92 & $-30.65 \%$ & 0.0706 & $106 \%$ & $-0.02+0.00 \mathrm{i}$ & 0.02 \\
$Z_{s}(13) @ T H D_{V}, @ R=1 \mathrm{pu}$ & 8.06 & $-29.42 \%$ & 0.0667 & $100 \%$ & $0.60-0.28 \mathrm{i}$ & 0.66 \\
\hline
\end{tabular}

In addition, resistive SHI are easily implemented as a secondary control function of power electronic energy supplies because there is no measurement needed of the polluting current. Through the simplicity of the compensator devices, they can be spread throughout the power system (e.g. distributed generation) and deliver a major contribution to the damping of the harmonic propagation. As a result, fewer conventional passive or active filters will be required in order to satisfy the statutory harmonic limits.

\section{ACKNOWLEDGEMENTS}

The research of Wouter Ryckaert is supported by the Institute for the Promotion of Innovation by Science and Technology in Flanders (IWT).

The research of Jozef Ghijselen is partially supported by the Fund for Scientific Research Flanders (FWO-Vlaanderen)

\section{REFERENCES}

[1] I.M. Nejdawi, A.E. Emanuel, D.J. Pileggi, M.J. Corridori, and R.D. Archambeault, "Harmonic trend in NE USA: a preliminary survey," IEEE Transactions on Power Delivery, vol. 14, no. 4, pp. 1488-1494, Oct. 1999.

[2] IEEE Task Force on the effect of harmonics on equipment, "Effects of harmonics on equipment," IEEE Transactions on Power Delivery, vol. 8, no. 2, pp. 672-680, Apr. 1993.

[3] W. Xu, X. Liu, and Y. Liu, "Assessment of harmonic resonance potential for shunt capacitor applications," Electric Power Systems Research, vol. 57, no. 2, pp. 97 - 104, March 2001.

[4] F.Z. Peng, "Application issues of active power filters," IEEE Industry Applications Magazine, vol. 4, no. 5, pp. 21-30, Sept. 1998.

[5] H. Akagi, "New trends in active power line conditioners," IEEE Transactions on Industry Applications, vol. 32, no. 6, pp. 1312-1322, Nov. 1996.

[6] H. Akagi, H. Fujita, and K. Wada, "A shunt active filter based on voltage detection for harmonic termination of a radial power distribution line," IEEE Transactions on Industry Applications, vol. 35, no. 3, pp. 638-645, Nov. 1999.

[7] J.A.L. Ghijselen, W.R.A. Ryckaert, and J.A.A. Melkebeek, "Required load behavior for power quality improvement," Proceedings of the IEEE Power Engineering Society Summer Meeting 2002, Chicago, USA, 2125 July 2002, vol. 2, pp. 998-1003.

[8] A. Mansoor, W.M. Grady, R.S. Thallam, M.T. Doyle, S.D. Krein,and M.J. Samotyj, "Effect of Supply Voltage Harmonics on the Input Current of Single-Phase Diode Bridge Rectifier Loads," IEEE Transactions on Power Delivery, vol. 10, no. 3, pp. 1416-1422, Jul. 1995.
[9] W.R.A. Ryckaert, J.A.L. Ghijselen, and J.A.A. Melkebeek, "Optimized loads for damping harmonic propagation," Proceedings of the IEEE Power Engineering Society Summer Meeting 2002, Chicago, USA, 2125 July 2002, vol. 2, pp. 818-823.

[10] E.F. El-Saadany, and M.M.A. Salama, "Reduction of the net harmonic current produced by single-phase non-linear loads due to attenuation and diversity effects," Electrical Power \& Energy Systems, vol. 20, no. 4, pp. 259-267, May 1998.

[11] IEC 61000-2-6 Technical Report, "Electromagnetic compatibility (EMC)-Part 2: Environment-Section 6: Assessment of the emission levels in the power supply of industrial plants as regards low-frequency conducted disturbances," International Electrotechnical Commission (IEC), Zürich, Switzerland, 1995.

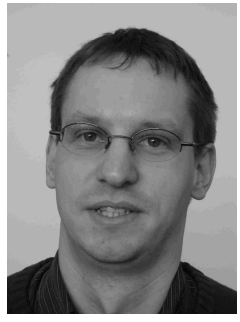

Wouter R.A. Ryckaert (M'02) received the degree of industrial engineer in electrical engineering from Kaho Sint-Lieven, Belgium, in 1998 and the M.Sc. degree in electrical and mechanical engineering from Ghent University, Belgium, in 2001. Since then, he has been with the Electrical Energy Laboratory (EELAB), Department of Electrical Energy, Systems and Automation (EESA) of Ghent University and is currently working towards a Ph.D. degree. His research interests include power quality and power electronics.

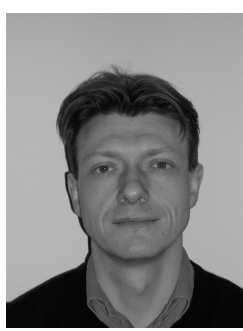

Jozef A.L. Ghijselen (S'89-M'90) received the M.Sc. and Ph.D. degrees from Ghent University, Belgium, in 1990 and 2001, respectively. Since then, he has been with the Electrical Energy Laboratory (EELAB), Department of Electrical Energy, Systems and Automation (EESA) of Ghent University. His research interests include power electronics and power quality.

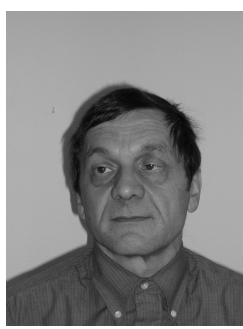

Jan A.A. Melkebeek (M'75-SM'83) received the Dr.Ing. degree in electrical and mechanical engineering, the Ph.D. degree in applied sciences, and the Dr.Habilitus degree in electrical and electronical power technology from Ghent University, Belgium, in 1975,1980 , and 1986, respectively. Since 1987, he has been a Professor in electrical engineering with the Engineering Faculty, Ghent University. His teaching activities and research interests include electrical machines, power electronics, variable frequency drives, and also control systems theory ap- 